\title{
Effects of feeding different amounts of milk replacer on growth performance and nutrient digestibility in Holstein calves to 2 months of age using different weaning strategies
}

\author{
R. N. Klopp, ${ }^{1} \oplus$ F. X. Suarez-Mena, ${ }^{2} \odot$ T. S. Dennis, ${ }^{2} \odot$ T. M. Hill, ${ }^{2} \odot$ R. L. Schlotterbeck, ${ }^{2} \odot$ \\ and G. J. Lascano ${ }^{1 *}$ \\ ${ }^{1}$ Department of Animal and Veterinary Sciences, Clemson University, Clemson, SC 29634 \\ ${ }^{2}$ Nurture Research Center, Provimi, Brookville, OH 45309
}

\section{ABSTRACT}

Growth and the digestibility of nutrients can be greatly affected by diet preweaning and the rate at which calves are weaned. A $2 \times 2$ factorial design [moderate (MOD) or high (HI) milk replacer (MR) feeding rates and abrupt (AB) or gradual (GR) weaning] was used to compare these effects. Calves $(\mathrm{n}=50)$ were randomly assigned to 1 of 4 treatments: MOD-AB, MOD-GR, $\mathrm{HI}-\mathrm{AB}$, and HI-GR. Calves assigned to MOD-AB were fed $0.66 \mathrm{~kg}$ of MR for the first $42 \mathrm{~d}$ and then $0.33 \mathrm{~kg}$ for the last $7 \mathrm{~d}$; those assigned to MOD-GR were fed $0.66 \mathrm{~kg}$ of $\mathrm{MR}$ for $28 \mathrm{~d}, 0.33 \mathrm{~kg}$ for $14 \mathrm{~d}$, and $0.17 \mathrm{~kg}$ for the last $7 \mathrm{~d}$; those assigned to HI-AB were fed 0.66 $\mathrm{kg}$ of MR for $7 \mathrm{~d}, 0.82 \mathrm{~kg}$ for $7 \mathrm{~d}, 1.1 \mathrm{~kg}$ for $28 \mathrm{~d}$, and $0.66 \mathrm{~kg}$ for the last $7 \mathrm{~d}$; and those assigned to HI-GR were fed $0.66 \mathrm{~kg}$ of $\mathrm{MR}$ for $7 \mathrm{~d}, 0.82 \mathrm{~kg}$ for $7 \mathrm{~d}, 1.1 \mathrm{~kg}$ for $14 \mathrm{~d}, 0.66 \mathrm{~kg}$ for $14 \mathrm{~d}$, and $0.33 \mathrm{~kg}$ for the last $7 \mathrm{~d}$. All calves received the same MR [25\% crude protein (CP), $17 \%$ fat; dry matter (DM) basis] and were given ad libitum access to water and a textured starter (42\% starch and $20 \% \mathrm{CP}$ ). On d 26 to 30 and d 45 to 49, a fecal sample was taken from 5 calves in each treatment via the rectum to estimate apparent digestibility coefficients $(\mathrm{dC})$. Apparent $\mathrm{dC}$ of $\mathrm{DM}$, organic matter, and fat were greater for HI versus MOD calves. Apparent $\mathrm{dC}$ of neutral detergent fiber, acid detergent fiber, and sugar were greater for MOD versus HI calves. Apparent $\mathrm{dC}$ of DM was greater for $\mathrm{AB}$ versus GR calves [90.9, $89.0 \pm 0.5384$ (standard error)], and the apparent $\mathrm{dC}$ of acid detergent fiber was greater for GR versus $A B$ calves $(39.5,32.3 \pm 1.67)$. Feed efficiency was greater for $\mathrm{HI}$ versus MOD and $\mathrm{AB}$ versus GR. There were no significant differences between $\mathrm{CP}$ or starch $\mathrm{dC}$ based on treatment, and no interactions were observed. Starter consumption was greater for MOD calves compared

Received June 24, 2019 .

Accepted August 14, 2019.

*Corresponding author: glascan@clemson.edu with HI calves, and GR calves consumed more than AB calves. These results suggest that providing calves high amounts of MR preweaning enhanced readily available nutrient $\mathrm{dC}$, but providing moderate amounts of $\mathrm{MR}$ resulted in increased fibrous fraction dC. Accordingly, the $\mathrm{AB}$ weaning strategy had higher $\mathrm{dC}$ for $\mathrm{DM}$ and organic matter, but there was a depression in fiber $\mathrm{dC}$. Key words: calf, growth, gradual weaning, milk replacer amount

\section{INTRODUCTION}

Neonatal calves are preruminants because the rudimentary development of this compartment affects function and the establishment of microbial communities (Steele et al., 2016). Thus, calves receive a high proportion of highly available nutrients (colostrum, milk, or milk replacer; MR) during the preweaning period to enable passive immunity and enhanced absorption (Gelsinger and Heinrichs, 2017). It has been shown that rumen development is improved in calves that are offered low to moderate amounts of MR to encourage the consumption of grain sources (Anderson et al., 1987; Suarez-Mena et al., 2011; Kertz and Loften, 2013). On the contrary, preweaning ADG are greater when increased amounts of MR are fed (Jasper and Weary, 2002; Chapman et al., 2017). Solid dry feed is necessary for a calf to transition successfully from preruminant to ruminant through the production of VFA (mainly butyrate and propionate), muscularization (optimal particle size influences physical stimulation and reduction of keratinization), and vascularization (Beharka et al., 1998; Coverdale et al., 2004; Suarez-Mena et al., 2015). Stimulation of healthy papillae development aids in the absorption of nutrients in the rumen as well as the establishment of microbial communities; these enhance adaptation to energy-dense and nutrient-diverse diets fed postweaning (Hill et al., 2010; Steele et al., 2016).

The first transition period in the newborn dairy animal is the postweaning period. This is a highly stressful 
time when rumen development and microbial establishment are challenged to adapt rapidly from being highly dependent on milk to depending on diverse sources of nutrients in the new grain mix (Khan et al., 2011). Thus, weaning strategies during this phase become extremely important to ameliorate possible digestive and health problems that these animals are exposed to (Baldwin et al., 2004; Hill et al., 2016a). Calves that are weaned abruptly or with minimal adaptation steps tend to have a burdensome transition to a completely solid diet, which can stunt growth and ADG as a result of suboptimal rumen development (Sweeney et al., 2010; Wood et al., 2015). However, calves that are weaned gradually transition better onto a solid-feed diet and do not show dramatically reduced ADG (Dennis et al., 2018).

These results suggest that weaning and postweaning strategies are of great influence on calf health, growth, and feed efficiency. The amount of milk or MR fed preweaning affects both rumen development and establishment of the microbial population, and weaning strategies seem to have a substantial effect on the performance of dairy calves after weaning. In the present experiment, 2 of these major factors were evaluated by assessing MR amount and weaning strategy to determine how they influence growth and nutrient digestibility of young dairy calves. Our hypothesis was that calves that were fed a moderate (vs. high) amount of MR during weaning and subjected to a gradual adaptation strategy to solid feed before weaning would have improved nutrient utilization and growth.

\section{MATERIALS AND METHODS}

\section{Animals, Facilities, and Treatments}

All animals were cared for as described in Guide for the Care and Use of Agricultural Animals in Research and Teaching (FASS, 2010) and under the approval of the institutional animal and care and use committee. Fifty Holstein bull calves, 2 to $3 \mathrm{~d}$ of age, were received from a single farm after traveling for $3.5 \mathrm{~h}$ to the Nurture Research Center (Brookville, $\mathrm{OH}$ ) on April 11, 2017. Before arriving, calves were housed in individual hutches with wire pens. They were fed $3 \mathrm{~L}$ of fresh colostrum within $1 \mathrm{~h}$ of birth followed by another $3 \mathrm{~L} 12 \mathrm{~h}$ later. Calves then received $2 \mathrm{~L}$ of pasteurized whole milk twice daily until they left the source facility. Upon arrival, calves were sorted into individual pens $(1.2 \mathrm{~m} \times 2.4 \mathrm{~m})$, with a rock tile-drained base and bedded with wheat straw, inside the facility with no added heat, natural ventilation, and curtain sides. The day after the calves arrived, they were weighed (initial BW
$=42 \pm 1.3 \mathrm{~kg}$ ), and a blood sample was taken intravenously. The blood was centrifuged at $3,000 \times g(\mathrm{VWR}$, Batavia, IL) at $20^{\circ} \mathrm{C}$ for 15 min to separate the serum, and then serum protein concentration was estimated using an optical refractometer (Atago USA Inc., Bellevue, WA). Calves were fed $0.66 \mathrm{~kg}$ of $\mathrm{MR}(\mathrm{DM})$ the first afternoon and the next morning. Then, calves were randomly assigned to 1 of 4 treatments (Figure 1) in a $2 \times 2$ factorial arrangement: (1) moderate MR rate and abrupt (1 step down) weaning strategy (MOD-AB; $0.66 \mathrm{~kg}$ for the first $42 \mathrm{~d}$ and $0.33 \mathrm{~kg}$ for the last $7 \mathrm{~d}$ a.m. only); (2) moderate MR rate and gradual (2 step down) weaning strategy (MOD-GR; $0.66 \mathrm{~kg}$ for $28 \mathrm{~d}$, then $0.33 \mathrm{~kg}$ for $14 \mathrm{~d}$ a.m. only, and $0.17 \mathrm{~kg}$ for $7 \mathrm{~d}$ a.m. only); (3) high MR rate and abrupt weaning strategy (HI-AB; $0.66 \mathrm{~kg}$ for $7 \mathrm{~d}, 0.82 \mathrm{~kg}$ for $7 \mathrm{~d}, 1.1 \mathrm{~kg}$ for $28 \mathrm{~d}$, and $0.66 \mathrm{~kg}$ for the last $7 \mathrm{~d}$ a.m. only); and (4) high MR rate and gradual weaning strategy (HI-GR; $0.66 \mathrm{~kg}$ for $7 \mathrm{~d}, 0.82 \mathrm{~kg}$ for $7 \mathrm{~d}, 1.1 \mathrm{~kg}$ for $14 \mathrm{~d}, 0.66$ $\mathrm{kg}$ for $14 \mathrm{~d}$ a.m. only, and $0.33 \mathrm{~kg}$ for the last $7 \mathrm{~d}$ a.m. only). After weaning through d 56, calves remained in individual pens with no MR consumption. The MOD treatments had 13 calves each, and the HI treatments had 12 calves each.

All calves received the same common MR (25\% CP, $17 \%$ fat; DM basis; $14 \%$ solids; Table 1), which was formulated with added synthetic AA (Hill et al., 2008b) and fatty acids (Hill et al., 2011). Milk replacer was fed in equal amounts twice daily at 0630 and $1530 \mathrm{~h}$. Calves were given ad libitum access to a texturized calf starter (20\% CP, $42 \%$ starch; DM basis; Table 1) and water for $56 \mathrm{~d}$. Starter consumption was recorded daily. Feces were scored daily on a scale of 1 to 5 , with 1 being normal and 5 being watery (modified from Kertz and Chester-Jones, 2004). Medical treatments were also reported daily. All calves were weighted on d 0, 7, 14, $21,28,35,42,49$, and 56 between approximately 1100 and $1300 \mathrm{~h}$. Body condition scores (1 being thin and 5 being obese; modified from Wildman et al., 1982) and hip widths (HW) were recorded every other week (d 0 , 14, 28, 42, and 56). Hip height $(\mathbf{H H})$ was measured at the beginning of the trial (d 0$)$ and at the end of the trial (d 56). The average temperature during the 56-d nursery phase was $19^{\circ} \mathrm{C}$, with a range of 2 to $35^{\circ} \mathrm{C}$. The average humidity during this period was $69 \%$, with a range of 12 to $100 \%$.

\section{Digestibility Estimates}

Five calves were randomly selected from each treatment (20 total) for fecal sampling to estimate diet apparent digestibility coefficients $(\mathbf{d C})$. Sampling was performed on d 26 to 30 and d 45 to 49 (indicated as d 


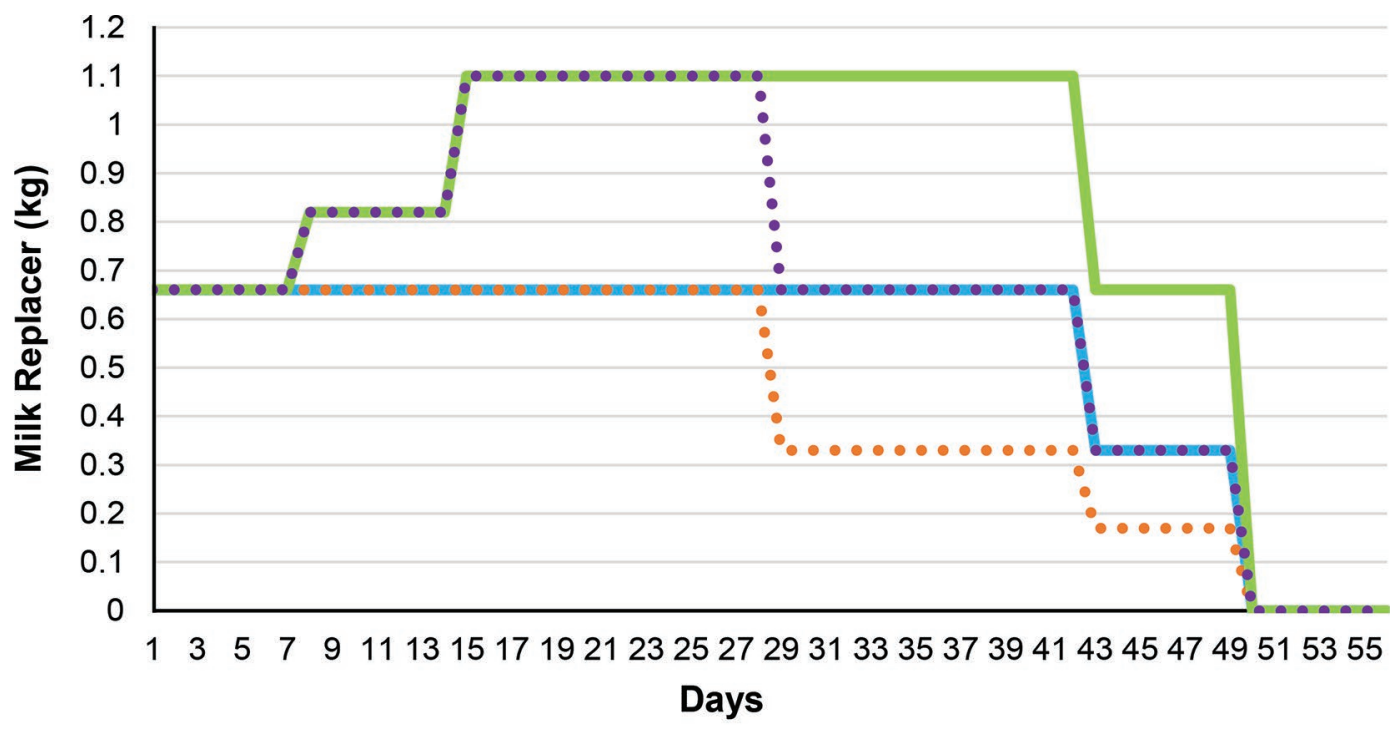

MOD-AB $\cdots \cdots M O D-G R$

HI-AB $\bullet \cdots \cdot H I-G R$

Figure 1. Milk replacer (MR) intakes for different feeding treatments during the nursery phase. MOD-AB = moderate MR rate and abrupt weaning strategy $(0.66 \mathrm{~kg}$ for the first $42 \mathrm{~d}$ and $0.33 \mathrm{~kg}$ for last $7 \mathrm{~d}$ a.m. only). MOD-GR = moderate MR rate and gradual weaning strategy $(0.66 \mathrm{~kg}$ for $28 \mathrm{~d}, 0.33 \mathrm{~kg}$ for $14 \mathrm{~d}$ a.m. only, and $0.17 \mathrm{~kg}$ for $7 \mathrm{~d}$ a.m. only). HI-AB = high MR rate and abrupt weaning strategy $(0.66 \mathrm{~kg}$ for 7 d, $0.82 \mathrm{~kg}$ for $7 \mathrm{~d}, 1.1 \mathrm{~kg}$ for $28 \mathrm{~d}$, and $0.66 \mathrm{~kg}$ for the last $7 \mathrm{~d}$ a.m. only). HI-GR = high MR rate and gradual weaning strategy (0.66 $\mathrm{kg}$ for 7 d, $0.82 \mathrm{~kg}$ for $7 \mathrm{~d}, 1.1 \mathrm{~kg}$ for $14 \mathrm{~d}, 0.66 \mathrm{~kg}$ for $14 \mathrm{~d}$ a.m. only, and $0.33 \mathrm{~kg}$ for the last $7 \mathrm{~d}$ a.m. only).

26 and 45 , respectively), and samples were composited by calf for each sampling period to estimate total-tract diet digestibility as described by Hill et al. (2016b). Fecal samples were systematically collected such that a total of 12 fecal samples were collected over the $4 \mathrm{~d}$ to represent every $2 \mathrm{~h}$ in a 24 -h period. Fecal grab samples were taken from the 5 calves randomly selected per treatment on d 26 and 45, frozen daily, combined on an equal wet weight basis, and subsampled for analysis. Acid-insoluble ash was used as an internal marker for feed and fecal samples taken during both periods (Hill et al., 2016b). Feed was offered for minimal refusals during the digestibility periods, and refusals were saved daily by pen, composited, and subsampled for analysis.

Table 1. Chemical composition (\% of DM unless otherwise noted) of experimental feeds

\begin{tabular}{lcr}
\hline Item & $\mathrm{MR}^{1}$ & \multicolumn{1}{c}{ Starter $^{2}$} \\
\hline $\mathrm{DM}(\%$ as fed $)$ & $96.8 \pm 1.10$ & $87.9 \pm 2.10$ \\
Ash & $6.0 \pm 0.62$ & $6.3 \pm 0.49$ \\
$\mathrm{CP}$ & $24.9 \pm 2.12$ & $20.7 \pm 2.25$ \\
Fat & $17.8 \pm 1.99$ & $3.5 \pm 0.34$ \\
ADF & - & $7.5 \pm 0.97$ \\
NDF & - & $14.2 \pm 1.96$ \\
Starch & - & $42.4 \pm 0.54$ \\
Sugar & - & $6.7 \pm 0.82$ \\
\hline
\end{tabular}

${ }^{1}$ Milk replacer manufactured from whey, whey protein concentrate, and animal fat.

${ }^{2}$ Contained $37 \%$ whole corn, $35 \%$ protein-mineral pellet, $25 \%$ whole oats, and $3 \%$ liquid molasses.

\section{Feed and Digestibility Analyses}

Every other bag of MR and starter was sampled and composited for nutrient analysis. Feeds, refusals, and feces were analyzed according to AOAC International (2000) for DM (oven method 930.15), ash (oven method 942.05), CP (Kjeldahl method 988.05), and fat (alkaline treatment with Röse-Gottlieb method 932.06 for MR; diethyl ether extraction method 2003.05 for starters and hay); NDF with ash (Van Soest et al., 1991) without sodium sulfite or $\alpha$-amylase; ADF with ash (Robertson and Van Soest, 1981); starch ( $\alpha$-amylase method; Hall, 2009); sugar (colorimetric method; DuBois et al., 1956); and acid insoluble ash (Van Keulen and Young, 1977).

\section{Statistical Analyses}

Data were analyzed as a completely randomized design with repeated measures when applicable to identify changes over time using PROC MIXED in SAS (version 9.4; SAS Institute Inc., Cary, NC). Initial BW was not included in the statistical model as a covariate because of no influence on the primary outcome measures. The statistical model was represented as follows:

$$
\begin{gathered}
\mathrm{Y}_{\mathrm{igjk}}=\mu+\mathrm{M}_{\mathrm{i}}+\mathrm{S}_{\mathrm{g}}+\mathrm{W}_{\mathrm{j}}+\mathrm{MS}_{(\mathrm{ig})}+\mathrm{WM}_{(\mathrm{ji})}+\mathrm{WS}_{(\mathrm{jg})} \\
+\mathrm{WMS}_{(\mathrm{jig})}+\mathrm{C}_{\mathrm{k}(\mathrm{ig})}+\mathrm{e}_{\mathrm{igjk}},
\end{gathered}
$$


Table 2. Performance of calves fed a moderate (MOD) or high (HI) rate of milk replacer using an abrupt (AB) or gradual (GR) weaning strategy

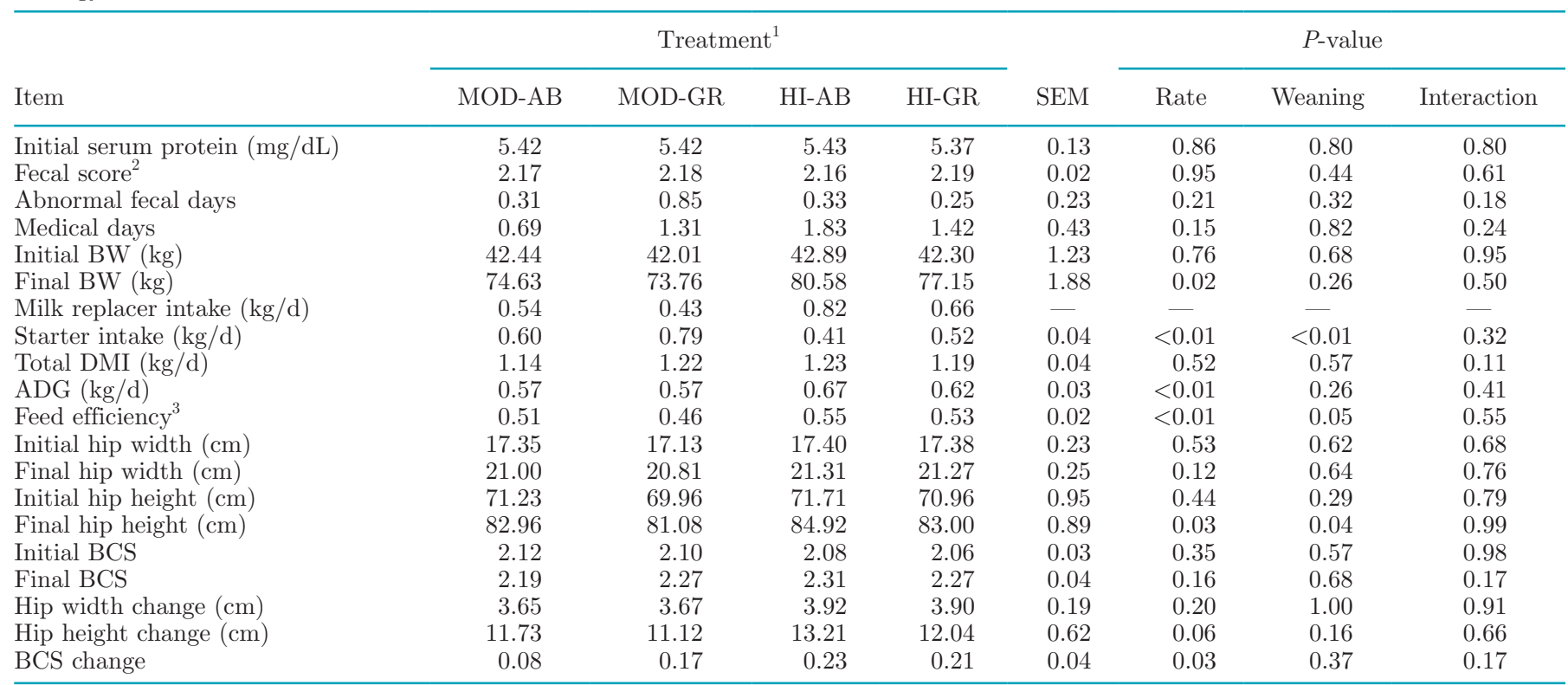

${ }^{1} \mathrm{MOD}-\mathrm{AB}=$ calves were fed $0.66 \mathrm{~kg}$ (DM basis) of milk replacer $(\mathrm{MR})$ for the first $42 \mathrm{~d}$ and then $0.33 \mathrm{~kg}$ for the last $7 \mathrm{~d}$. MOD-GR $=$ calves were fed $0.66 \mathrm{~kg}$ of MR for $28 \mathrm{~d}, 0.33 \mathrm{~kg}$ for $14 \mathrm{~d}$, and $0.17 \mathrm{~kg}$ for the last $7 \mathrm{~d}$. HI-AB = calves were fed $0.66 \mathrm{~kg}$ of $\mathrm{MR}$ for $7 \mathrm{~d}, 0.82 \mathrm{~kg}$ for $7 \mathrm{~d}$, $1.1 \mathrm{~kg}$ for $28 \mathrm{~d}$, and $0.66 \mathrm{~kg}$ for the last $7 \mathrm{~d}$. HI-GR = calves were fed $0.66 \mathrm{~kg}$ of $\mathrm{MR}$ for $7 \mathrm{~d}, 0.82 \mathrm{~kg}$ for $7 \mathrm{~d}, 1.1 \mathrm{~kg}$ for $14 \mathrm{~d}, 0.66 \mathrm{~kg}$ for $14 \mathrm{~d}$, and $0.33 \mathrm{~kg}$ for the last $7 \mathrm{~d}$.

${ }^{2} 1$ - to 5 -point system: $1=$ thick; $2=$ less thick; $3=$ abnormal like batter; $4=$ abnormal, watery with color; $5=$ abnormal, watery with little color.

${ }^{3}$ Body weight gain divided by milk replacer plus starter intake.

where $\mathrm{Y}_{\text {igjk }}$ is a continuous, dependent response variable and $\mu$ is the overall mean. The model includes terms for the fixed factors $\mathrm{MR}$ rate $\left(\mathrm{M}_{\mathrm{i}} ; \mathrm{i}=1,2\right)$, weaning strategy $\left(\mathrm{S}_{\mathrm{g}} ; \mathrm{g}=1,2\right)$, and week $\left(\mathrm{W}_{\mathrm{j}} ; \mathrm{j}=1\right.$ to 8$) ; \mathrm{MS}_{(\mathrm{ig})}$ is the interaction of $\mathrm{M}$ and $\mathrm{S}, \mathrm{WM}_{(\mathrm{ji})}$ is the interaction of $\mathrm{W}$ and $\mathrm{M}, \mathrm{WS}_{(\mathrm{jg})}$ is the interaction of $\mathrm{W}$ and $\mathrm{S}$, and $\mathrm{WMS}_{(\mathrm{jig})}$ is the interaction of $\mathrm{W}, \mathrm{M}$, and $\mathrm{S} ; \mathrm{C}_{\mathrm{k}(\mathrm{ig})}$ is the random effect of calf within treatment (M and $\mathrm{S}$ ), and $\mathrm{e}_{\mathrm{igjk}}$ is the residual error. Calf was the experimental unit $(n=50$ for the growth measurements and $n=20$ for digestibility).

Body weight and intake data were grouped by week, and structural measures and BCS data were grouped by $14-d$ periods. The digestibility data were analyzed by individual 5 -d collection periods as well as for the entire 56-d period. In the mixed models with repeated measurements, the first-order autoregressive structure was selected as the appropriate covariance structure based on Akaike information criterion. Exceptions were abnormal fecal score days and medical days, which were summed over the $56 \mathrm{~d}$ and analyzed using Kruskal-Wallis test with PROC NPAR1WAY in SAS. Analysis of variance followed by Fisher's protected least significant difference test were used to evaluate the terms in the model. Means were separated using the PDIFF option in SAS for weekly measurements where appropriate. $P$-values, least squares means, and standard errors of least squares means are presented in Tables 2 and 3 . Statistical significance was declared at $P \leq 0.05$, and trends were discussed at $0.10 \geq P \geq 0.05$.

\section{RESULTS AND DISCUSSION}

The chemical composition of starter and MR is presented in Table 1. Treatments were planned to differ mainly in MR intake rate and weaning strategy. Therefore, nutrient composition was the same among experimental treatments. No significant differences were reported among the 4 treatments for fecal score, abnormal fecal days, or medical days (Table 2). This indicates that MR feeding rate and weaning method had no effect on calf health during the completion of the weaning period in the current study.

\section{MR Feeding Rate Effect}

Growth Performance. Initial measurements (serum protein, BW, HW, HH, and BCS) did not differ between calves (Table 2). This indicates that all calves started the study with similar structural measurements 
Table 3. Apparent digestibility coefficients of nutrients in calves during the nursery phase of the trial as influenced by the 4 treatments

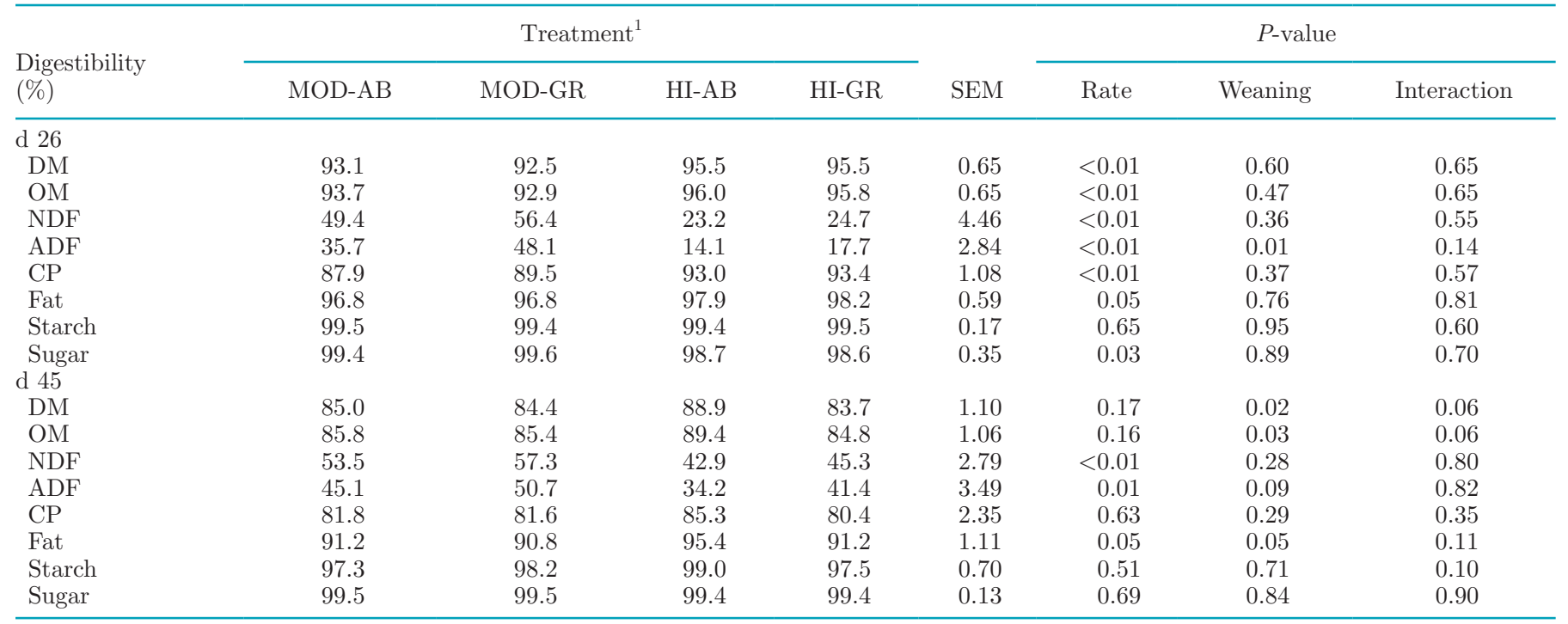

${ }^{1} \mathrm{MOD}-\mathrm{AB}=$ calves were fed $0.66 \mathrm{~kg}$ (DM basis) of milk replacer $(\mathrm{MR})$ for the first $42 \mathrm{~d}$ and then $0.33 \mathrm{~kg}$ for the last $7 \mathrm{~d}$. MOD-GR $=$ calves were fed $0.66 \mathrm{~kg}$ of $\mathrm{MR}$ for $28 \mathrm{~d}, 0.33 \mathrm{~kg}$ for $14 \mathrm{~d}$, and $0.17 \mathrm{~kg}$ for the last $7 \mathrm{~d}$. HI-AB = calves were fed $0.66 \mathrm{~kg}$ of $\mathrm{MR}$ for $7 \mathrm{~d}, 0.82 \mathrm{~kg}$ for $7 \mathrm{~d}$, $1.1 \mathrm{~kg}$ for $28 \mathrm{~d}$, and $0.66 \mathrm{~kg}$ for the last $7 \mathrm{~d}$. HI-GR = calves were fed $0.66 \mathrm{~kg}$ of $\mathrm{MR}$ for $7 \mathrm{~d}, 0.82 \mathrm{~kg}$ for $7 \mathrm{~d}, 1.1 \mathrm{~kg} \mathrm{for} 14 \mathrm{~d}, 0.66 \mathrm{~kg}$ for $14 \mathrm{~d}$, and $0.33 \mathrm{~kg}$ for the last $7 \mathrm{~d}$.

and that absorption of IgG from colostrum was adequate (Calloway et al., 2002). As expected, starter consumption was greater for calves consuming a moderate amount of MR compared with those consuming a high amount $(P<0.01)$. Decreased preweaning starter consumption in calves with high MR intake has been reported in many studies (Terré et al., 2007; Hill et al., 2016a; Dennis et al., 2018). This trend has been attributed to HI calves fulfilling a high amount of their nutrient requirements from MR, therefore reducing starter consumption. Figure 2 depicts starter consumption for each treatment by week. From wk 4 to 8 of the study, MOD calves consumed significantly greater starter compared with HI calves (wk 4-8; $P<0.01$ ). Similarly, MOD-GR calves had significantly greater starter consumption compared with calves in the other treatments $(P<0.01)$, MOD-AB and HI-GR calves consumed a similar amount, and HI-AB calves consumed significantly less starter compared with calves in the other treatments. High soluble carbohydrate intake from calf starter initiates rumen development by stimulating the proliferation of microbes within the rumen and through the production of VFA (Suárez et al., 2006). These VFA are produced through the microbial fermentation of carbohydrates. Particularly, butyrate stimulates rumen papillae and epithelial development, allowing the rumen to become even more effective at digesting solid feeds and absorbing nutrients (Tamate et al., 1962). Dennis et al. (2018) reported a similar trend in starter intake when calves were fed a similar
MR regimen (0.66, 0.82, 1.10, and ad libitum MR DMI; $\mathrm{kg} / \mathrm{d}$ ) and associated this trend with delayed rumen development and the need for HI calves to undertake later and gradual weaning (Hill et al., 2016a).

Average daily gain $(\mathrm{kg} / \mathrm{d}$ ), feed efficiency (gain, $\mathrm{kg}$ : feed, $\mathrm{kg} ; \mathbf{F E}$ ), final $\mathrm{HH}$, final $\mathrm{BW}$, and $\mathrm{BCS}$ change were greater $(P<0.05)$ and $\mathrm{HH}$ change tended to be greater $(P=0.06)$ for HI calves compared with MOD calves. Several studies have reported this similar increase in ADG in calves fed increased amounts of MR (Hill et al., 2007, 2010; Terré et al., 2007; Dennis et al., 2018). Terré et al. (2007) did not report effects on FE, $\mathrm{HH}$, or BCS, but they observed greater BW at weaning in calves fed less MR. This could be partially attributed to the fact that this study started feeding calves different amounts of MR around $20 \mathrm{~d}$ of age. The first 2 to 3 wk of age are vital for enhanced growth; however, this study almost completely missed that period of optimizing calf growth pre-weaning (Stamey et al., 2012). This is evident in a report by Kertz et al. (1979) that showed that calves have the ability to achieve enough growth and development to be weaned at $28 \mathrm{~d}$ of age. Dennis et al. (2018) also reported greater FE and ADG for calves receiving greater amounts of $\mathrm{MR}$ through $\mathrm{d} 56$. The fact that calves on high MR had increased final $\mathrm{HH}$, final $\mathrm{BW}$, and $\mathrm{BCS}$ change is consistent with their increased ADG, which can be attributed to the increased FE and intake of highly digestible sources of nutrients such as MR. These results indicate that high MR intake promoted higher BW and growth performance before 


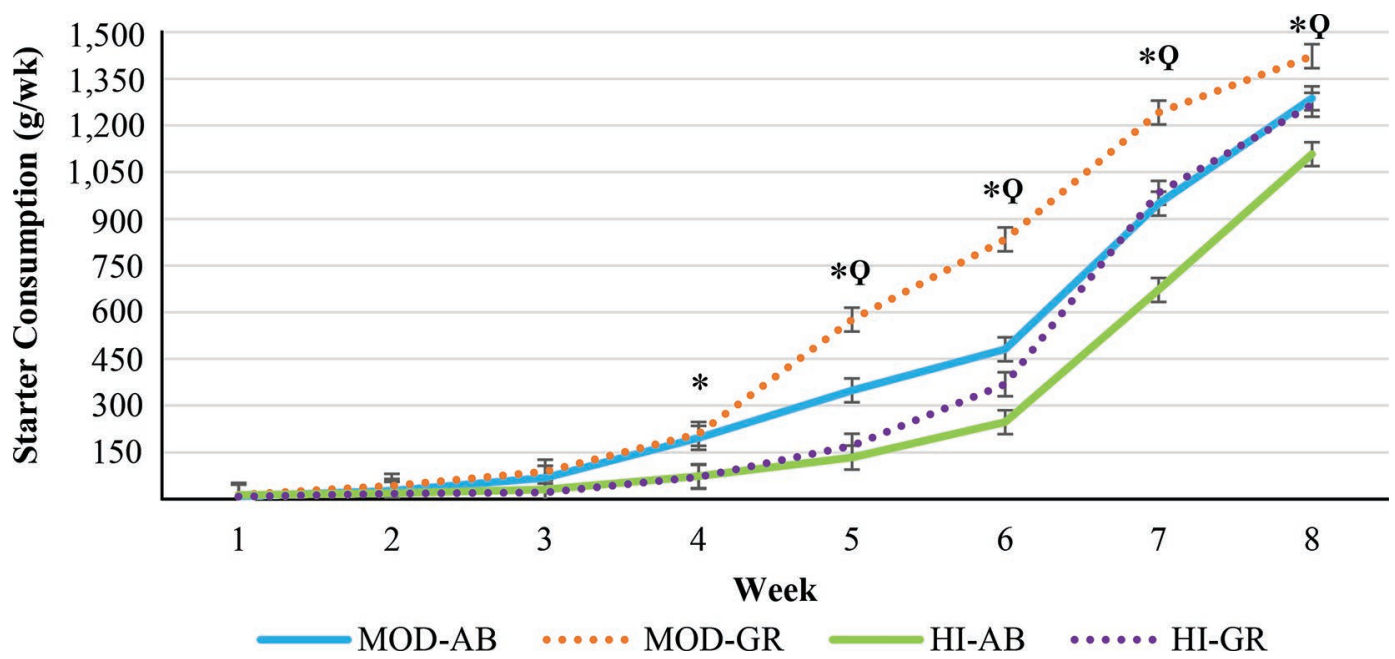

Figure 2. Mean starter intake for different feeding treatments during the nursery phase. Error bars indicate SE. Weaning strategy effect (Q; $P<0.05)$ and milk replacer $(\mathrm{MR})$ rate effect $(* ; P<0.05)$ reflect weekly effects; no interactions were detected. $\mathrm{MOD}-\mathrm{AB}=\mathrm{moderate} \mathrm{MR}$ rate and abrupt weaning strategy $(0.66 \mathrm{~kg}$ for the first $42 \mathrm{~d}$ and $0.33 \mathrm{~kg}$ for last $7 \mathrm{~d}$ a.m. only). MOD-GR = moderate MR rate and gradual weaning strategy ( $0.66 \mathrm{~kg}$ for $28 \mathrm{~d}, 0.33 \mathrm{~kg}$ for $14 \mathrm{~d}$ a.m. only, and $0.17 \mathrm{~kg}$ for $7 \mathrm{~d}$ a.m. only). HI-AB = high MR rate and abrupt weaning strategy ( 0.66 $\mathrm{kg}$ for $7 \mathrm{~d}, 0.82 \mathrm{~kg}$ for $7 \mathrm{~d}, 1.1 \mathrm{~kg}$ for $28 \mathrm{~d}$, and $0.66 \mathrm{~kg}$ for the last $7 \mathrm{~d}$ a.m. only). HI-GR = high MR rate and gradual weaning strategy (0.66 $\mathrm{kg}$ for $7 \mathrm{~d}, 0.82 \mathrm{~kg}$ for $7 \mathrm{~d}, 1.1 \mathrm{~kg}$ for $14 \mathrm{~d}, 0.66 \mathrm{~kg}$ for $14 \mathrm{~d}$ a.m. only, and $0.33 \mathrm{~kg}$ for the last $7 \mathrm{~d} \mathrm{a.m}$. only).

weaning (Table 2). This is likely due to increased MR consumption delivering a higher amount of available nutrients (Khan et al., 2007a), allowing calves to utilize greater quantities of nutrients for growth and development.

Figure 3 outlines BW change for each treatment by week. Before wk 3, there was not a significant difference in BW based on MR feeding rate or weaning strategy. It is consequential that we did not see a significant difference in $\mathrm{BW}$ during this period because MR rates were not different for the first week of the study, and it was not until $\mathrm{d} 15$ that high-MR calves started to receive almost double the amount of $\mathrm{MR}$ as the MOD calves. The HI treatments were designed to allow calves to become acclimated to that higher amount of MR, so their MR amounts were increased over 2 wk from 0.66 to $1.1 \mathrm{~kg}$ of MR (DM). At the end of wk 3, which is the first week that $\mathrm{HI}$ calves began receiving $1.1 \mathrm{~kg}$ of MR (DM), HI calves had significantly greater BW ( $P$ $<0.01$ ). This same pattern was observed through wk 8 (wk 4-8; $P<0.01$ ). Stamey et al. (2012) reported similar results for BW: as early as 2 to 3 wk of age and continued through wk 10, high-MR calves had a significantly greater BW compared with low-MR calves. During wk 6,7, and 8, we observed that HI-AB calves had significantly greater BW compared with all other treatments. This is a result of HI-AB calves consuming a greater amount of MR compared with the MOD calves and consuming greater MR for a longer period compared with HI-GR calves. This increased MR con- sumption leads to increased nutrient availability, which the animal can then use for growth and development.

The FE average during the entire experimental period was greater in $\mathrm{HI}$ calves than in MOD calves in agreement with previous experiments with intensive milk feeding programs in preweaning calves (Khan et al., 2007a,b; Davis Rincker et al., 2011; Dennis et al., 2018). This can be attributed to the greater nutrient intake above what is needed for maintenance (Bartlett et al., 2006). Figure 4 depicts the FE during the $8 \mathrm{wk}$ of the experiment; there was a significantly greater FE from wk 2 to 4 and at wk 6 and 8 for the HI group. This is consistent with similar experiments reporting FE weekly during the preweaning period (Stamey et al., 2012) and with reports in the literature related to the early advantage of providing more milk or MR during the first $28 \mathrm{~d}$ (Kertz et al., 1979; Flower and Weary, 2001). Superiority in FE continues until wk 8 and results in HI-GR calves having the highest FE $(P$ $<0.05$ ) for the aforementioned weeks, resulting in an FE of 0.64 versus $0.40,0.39$, and 0.49 for the MOD-AB, MOD-GR, and HI-AB groups, respectively. Thus, in the present experiment, gradual weaning seems to be effective for $\mathrm{FE}$ when used in high-MR feeding regimens.

Diet Digestibility. Table 3 outlines the apparent $\mathrm{dC}$ of nutrients at $\mathrm{d} 26$ and 45 and the average for the 2 periods (combined) to identify overall digestibility differences for the 56-d nursery phase. Apparent dC of $\mathrm{DM}, \mathrm{OM}$, and fat were greater $(P<0.05)$ for $\mathrm{HI}$ versus 
MOD calves. Apparent dC of NDF, ADF, and sugar were greater $(P<0.05)$ for MOD versus HI. There were no significant differences between $\mathrm{CP}$ or starch apparent dC based on treatment. Terré et al. (2007) also reported greater apparent $\mathrm{dC}$ for $\mathrm{NDF}$ in calves fed lower amounts of MR; they did not report on $\mathrm{ADF}$, fat, starch, or sugar dC. However, they also observed greater apparent $\mathrm{dC}$ for $\mathrm{DM}$ and $\mathrm{OM}$ in calves fed a lower amount of MR, which is the opposite of what we report in the present experiment. They reported greater apparent $\mathrm{CP} \mathrm{dC}$ in calves fed lower MR, whereas we did not see any differences between treatments. These differences could be because they measured digestibility only once (the week after weaning) and we measured it twice (during the nursery phase and 1 wk before weaning). A calf's digestive tract goes through many changes at weaning, which could be the cause of this variation. Our results suggest that calves receiving high amounts of MR preweaning have enhanced readily available nutrient $\mathrm{dC}$ but that calves receiving moderate amounts of MR have increased fibrous feed fraction digestion.

Table 3 shows the diet digestibility measurements for d 26. Apparent dC of DM $(P<0.01)$, OM $(P<$ $0.01)$, CP $(P<0.01)$, and fat $(P=0.05)$ were greater for HI calves than for MOD calves. Apparent $\mathrm{dC}$ of NDF $(P<0.01)$, ADF $(P<0.01)$, and sugar $(P=$ $0.03)$ were greater for MOD calves than for HI calves.
Dennis et al. (2018) evaluated digestibility on d 35 and reported greater apparent $\mathrm{dC}$ for $\mathrm{DM}, \mathrm{OM}, \mathrm{CP}$, and fat in high-MR calves as well as greater apparent $\mathrm{dC}$ for NDF in MOD calves; they did not report sugar $\mathrm{dC}$. These results support the observation in the current experiment. It has been reported that up to 4 to 5 wk of age, calves receiving greater amounts of $\mathrm{MR}$ are more efficient at digesting DM, OM, CP, and fat, whereas calves receiving a moderate feeding rate are more efficient at digesting some fibrous fractions (Hill et al., 2008a). As mentioned earlier, Khan et al. (2007a) reported similar observations: like in our MOD treatment, calves with greater starter consumption had earlier rumen development and increased fermentation capabilities, allowing for the digestion and absorption of fibrous feed fractions. Similar to our HI treatment, greater milk consumption led to intensified highly digestible nutrient availability, which is linked to greater gain and body measurements.

Digestibility for the last week before suspending MR feeding is presented in Table 3. Apparent dC of NDF $(P<0.01)$ and $\mathrm{ADF}(P=0.01)$ was greater for MOD calves than for HI calves. This indicates that MOD calves have a more developed rumen compared with HI calves, allowing them to have enhanced fiber $\mathrm{dC}$ (Steele et al., 2016). Apparent dC of fat was greater for HI calves than for MOD calves $(P=0.05)$. Dennis et al. (2018) reported digestibility on d 49 and observed

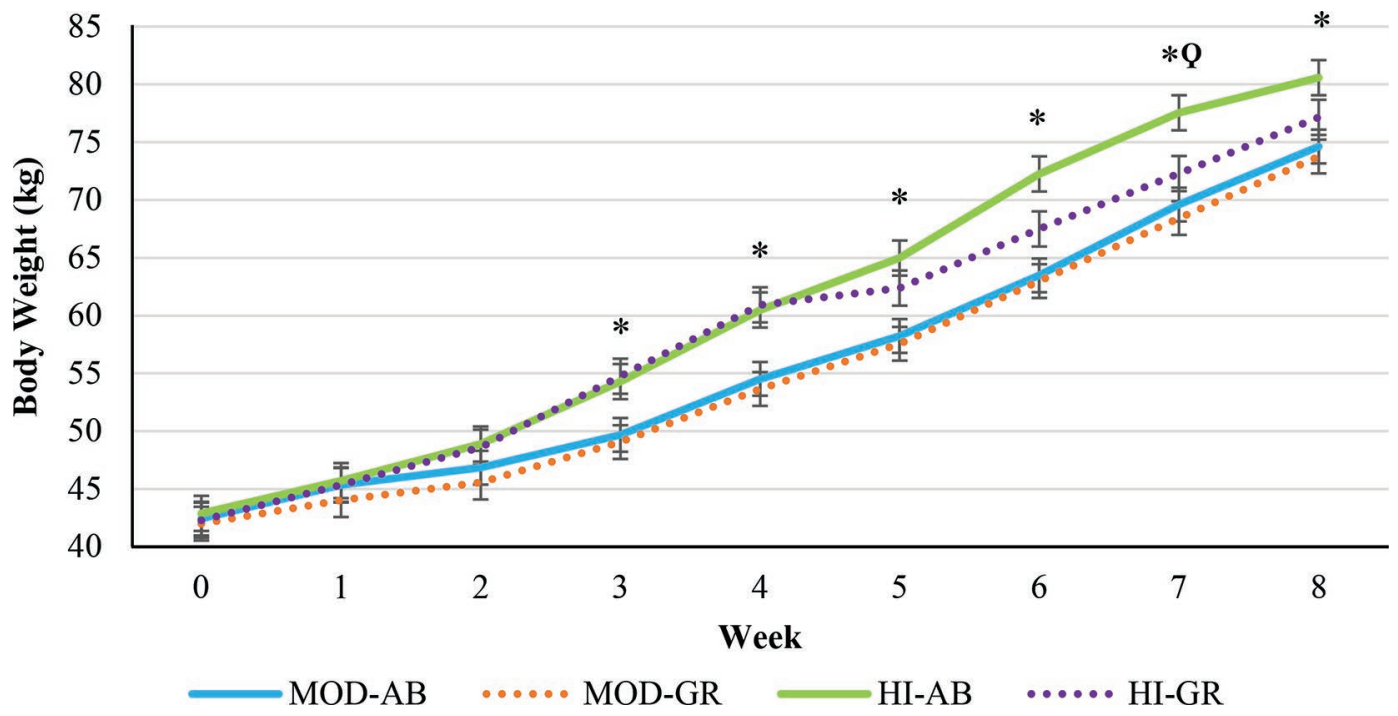

Figure 3. Mean weekly BW for different feeding treatments during the nursery phase. Error bars indicate SE. Weaning strategy effect (Q; $P<0.05)$ and milk replacer $(\mathrm{MR})$ rate effect $(* ; P<0.05)$ reflect weekly effects; no interactions were detected. MOD-AB $=$ moderate MR rate and abrupt weaning strategy $(0.66 \mathrm{~kg}$ for the first $42 \mathrm{~d}$ and $0.33 \mathrm{~kg}$ for last $7 \mathrm{~d}$ a.m. only). MOD-GR = moderate MR rate and gradual weaning strategy $(0.66 \mathrm{~kg}$ for $28 \mathrm{~d}, 0.33 \mathrm{~kg}$ for $14 \mathrm{~d}$ a.m. only, and $0.17 \mathrm{~kg}$ for $7 \mathrm{~d}$ a.m. only). HI-AB = high MR rate and abrupt weaning strategy (0.66 $\mathrm{kg}$ for $7 \mathrm{~d}, 0.82 \mathrm{~kg}$ for $7 \mathrm{~d}, 1.1 \mathrm{~kg}$ for $28 \mathrm{~d}$, and $0.66 \mathrm{~kg}$ for the last $7 \mathrm{~d}$ a.m. only). HI-GR = high MR rate and gradual weaning strategy (0.66 $\mathrm{kg}$ for $7 \mathrm{~d}, 0.82 \mathrm{~kg}$ for $7 \mathrm{~d}, 1.1 \mathrm{~kg}$ for $14 \mathrm{~d}, 0.66 \mathrm{~kg}$ for $14 \mathrm{~d}$ a.m. only, and $0.33 \mathrm{~kg}$ for the last $7 \mathrm{~d}$ a.m. only). 
greater apparent NDF and ADF digestibility for MOD versus HI calves, but did not see any differences in fat dC. A possible explanation to for this effect is that HI calves had a greater lipid intake from MR ( $50 \%$ higher), which is more digestible than fat contained in starter (Chapman et al., 2017).

Throughout the 56-d period, NDF and ADF digestibility remained greater for MOD calves than for HI calves $(P<0.01)$. On d 26 , sugar apparent $\mathrm{dC}$ was also greater for MOD calves than for HI calves, but by d 45, this significant difference was lost. On d 26, DM, OM, CP, and fat digestibility were all greater $(P$ $<0.01)$ for HI calves than for MOD calves $(P<0.05)$, but on d 45, only fat digestibility remained significantly greater for HI calves. This would indicate that early in the preweaning period, when HI calves are consuming a greater amount of MR compared with MOD calves, they are more efficient at digesting DM, OM, CP, and fat. However, later during the nursery phase, once MOD calves start to consume calf starter at greater rates, HI calves lose their advantage of having higher $\mathrm{dC}$ for DM, OM, and CP. Calves consuming moderate amounts of MR seem to be more apt at digesting NDF and ADF throughout the entire nursery phase. These results concur with those reported by Khan et al. (2007a), who concluded that calves consuming more milk (20 vs. $10 \%$ BW) have higher nutrient availability, leading to greater gain and structural growth, and that early consumption of starter by calves leads to a more metabolically developed rumen, allowing them to more efficiently digest and absorb fibrous feed fraction. Another possible explanation for the increased ADF and NDF digestibility seen in moderate-MR calves is a more developed and active fibrolytic bacteria population (Anderson et al., 1987; Terré et al., 2007). Consequently, reduced MR consumption resulted in increased starter consumption, leading to the earlier development of the rumen and greater fibrous fraction digestion with no differences in $\mathrm{dC}$ for readily available carbohydrates such as starch and sugar.

\section{Weaning Strategy Effect}

Growth Performance. Starter consumption was greater for GR calves compared with $\mathrm{AB}$ calves $(P<$ 0.01). Sweeney et al. (2010) used 4 weaning methods to assess starter consumption and reported that gradually weaned calves consumed more starter compared with abruptly weaned calves. Stater intake was not different until wk 5 (Figure 2), when MOD calves had a steep upsurge in consumption and maintained this pattern until the end of the weaning period. Dennis et al. (2018) reported similar effects when MR was offered using a similar weaning protocol. Final HH was greater for abruptly weaned calves compared with gradually weaned calves $(P=0.04)$. It is noteworthy that $\mathrm{FE}$ reached its nadir for $\mathrm{HI}$ in wk 5 and for MOD in wk 4 (Figure 4). Thus, it seems that high levels of MR allow

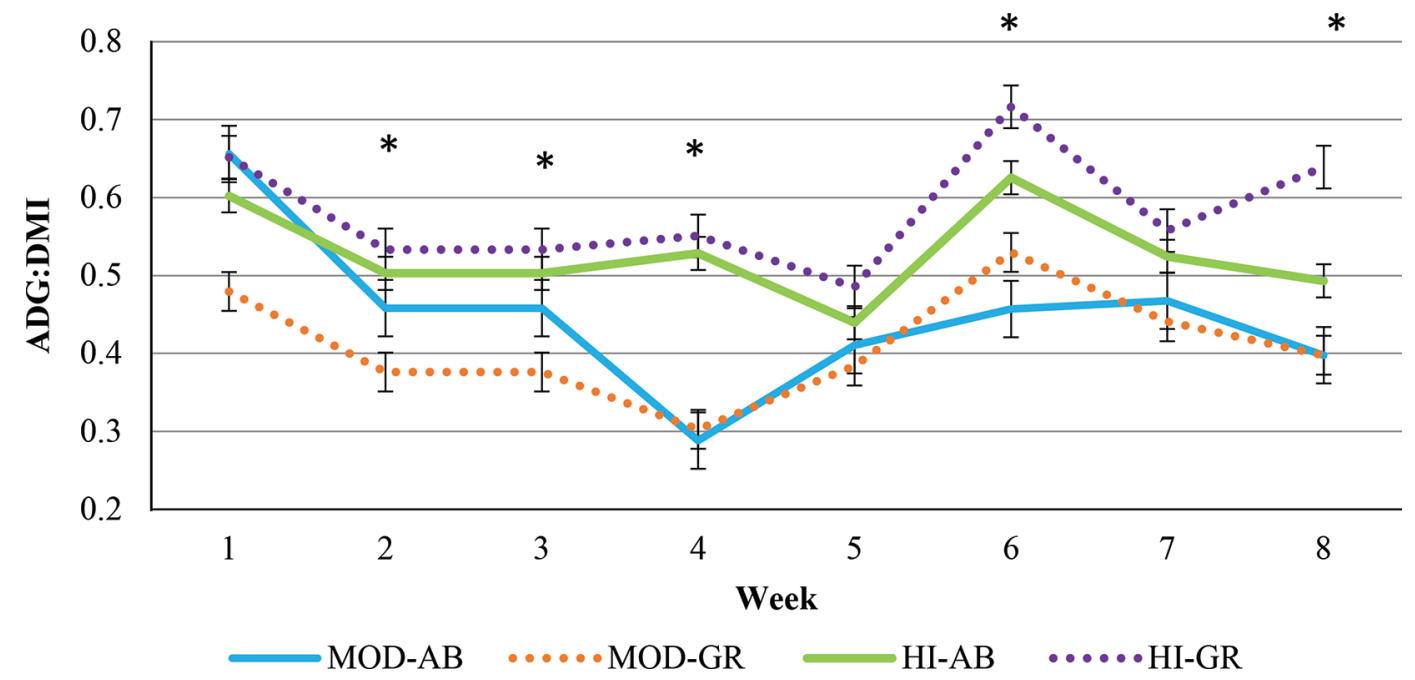

Figure 4. Mean weekly feed efficiency for different feeding sequences during the nursery phase. Error bars indicate SE. Milk replacer (MR) rate effect $(* ; P<0.05)$ reflects weekly effects; no weaning strategy effect or interactions detected. MOD-AB = moderate MR rate and abrupt weaning strategy $(0.66 \mathrm{~kg}$ for the first $42 \mathrm{~d}$ and $0.33 \mathrm{~kg}$ for last $7 \mathrm{~d}$ a.m. only). MOD-GR = moderate MR rate and gradual weaning strategy $(0.66 \mathrm{~kg}$ for $28 \mathrm{~d}, 0.33 \mathrm{~kg}$ for $14 \mathrm{~d}$ a.m. only, and $0.17 \mathrm{~kg}$ for $7 \mathrm{~d}$ a.m. only). HI-AB = high MR rate and abrupt weaning strategy $(0.66 \mathrm{~kg}$ for 7 $\mathrm{d}, 0.82 \mathrm{~kg}$ for $7 \mathrm{~d}, 1.1 \mathrm{~kg}$ for $28 \mathrm{~d}$, and $0.66 \mathrm{~kg}$ for the last $7 \mathrm{~d}$ a.m. only). HI-GR = high MR rate and gradual weaning strategy (0.66 $\mathrm{kg}$ for 7 d, $0.82 \mathrm{~kg}$ for $7 \mathrm{~d}, 1.1 \mathrm{~kg}$ for $14 \mathrm{~d}, 0.66 \mathrm{~kg}$ for $14 \mathrm{~d}$ a.m. only, and $0.33 \mathrm{~kg}$ for the last $7 \mathrm{~d}$ a.m. only). 
FE to remain higher for a longer period of time and that when paired with gradual weaning after reaching this lower FE, the introduction of higher starter intake results in greater $\mathrm{FE}$ for $\mathrm{GR}$ calves. The $\mathrm{AB}$ calves received higher amounts of $\mathrm{MR}$ for a longer period compared with the GR calves. Khan et al. (2007a) saw the opposite effect on $\mathrm{HH}$ when comparing conventional weaning (fed 10\% BW in MR for $44 \mathrm{~d}$ ) and step weaning (fed $20 \% \mathrm{BW}$ in MR for $23 \mathrm{~d}$, reduced to $10 \%$ from d 24-28, and remained at $10 \%$ for next $16 \mathrm{~d}$ ). This inconsistency could be due to treatment definitions. The step diet is similar to our HI-GR treatment, and the conventional diet is similar to our MOD-AB treatment. The combination of high MR with gradual weaning could be the key to increasing both starter consumption and growth. Hill et al. (2012) also compared abrupt weaning $(0.66 \mathrm{~kg} / \mathrm{d}$ for $39 \mathrm{~d}$ and then $0.33 \mathrm{~kg} / \mathrm{d}$ from d 40-42) and gradual weaning $(0.82 \mathrm{~kg} / \mathrm{d}$ from d $0-5,0.96 \mathrm{~kg} / \mathrm{d}$ from d $6-28,0.82 \mathrm{~kg} / \mathrm{d}$ from d $29-32$, $0.55 \mathrm{~kg} / \mathrm{d}$ from d 33-36, $0.41 \mathrm{~kg} / \mathrm{d}$ from d $37-39$, and $0.21 \mathrm{~kg} / \mathrm{d}$ from d 40-42). They reported greater BW and ADG, greater starter DMI from d 43 to 56, and greater FE from d 43 to 56 in gradually weaned calves. As planned, our $\mathrm{AB}$ calves were allowed to consume a greater amount of MR for a longer period of time, which might have induced greater structural growth such as greater HH. Weaning calves gradually leads to more starter consumption and lower structural growth $(\mathrm{HH})$. There were no interactions between weaning strategy and MR feeding rate for growth performance. This increased starter consumption seen in GR versus $\mathrm{AB}$ calves could enhance the transition performance of calves fed high amounts of MR.

Diet Digestibility. Apparent dC of DM $(P=0.05)$ was greater for $\mathrm{AB}$ calves than for GR calves, there was a trend for greater $\mathrm{OM}(P=0.06) \mathrm{dC}$ for $\mathrm{AB}$ calves than for GR calves, and the apparent $\mathrm{dC}$ of $\mathrm{ADF}(P=$ 0.01 ) was greater for GR calves than for AB calves. No significant interactions were observed between weaning strategy and MR feeding rate for diet digestibility. Table 3 shows the diet digestibility measurements for d 26. Apparent $\mathrm{dC}$ of $\operatorname{ADF}(P=0.01)$ was greater for gradual versus abrupt weaning. This is surprising because weaning strategy reductions did not start until d 28. Dennis et al. (2018) reported no differences at d 35 between calves fed high amounts of MR that were weaned abruptly $(0.87 \mathrm{~kg}$ of DM/d for $4 \mathrm{~d}, 1.09 \mathrm{~kg}$ for $42 \mathrm{~d}$, and $0.54 \mathrm{~kg}$ for $7 \mathrm{~d}$ ) and those weaned gradually $(0.87 \mathrm{~kg}$ of $\mathrm{DM} / \mathrm{d}$ for $4 \mathrm{~d}, 1.09 \mathrm{~kg}$ for $35 \mathrm{~d}, 0.87 \mathrm{~kg}$ for $4 \mathrm{~d}, 0.66 \mathrm{~kg}$ for $4 \mathrm{~d}, 0.44 \mathrm{~kg}$ for $3 \mathrm{~d}$, and $0.22 \mathrm{~kg}$ for 3 d). Thus, individual variation in the capability of calves digesting more recalcitrant fiber fraction can play an important role in responses to different dietary provisions during preweaning.
Diet digestibility measurements for d 45 are presented in Table 3. Apparent dC of DM $(P=0.02)$ and OM $(P=0.03)$ were greater for AB calves than for GR calves, and this was mainly influenced by the trend of HI-AB being greater than HI-GR and the other 2 MOD treatments (rate $\times$ weaning interaction, $P=$ 0.06). In addition, apparent $\mathrm{dC}$ of fat was greater for abrupt versus gradual weaning $(P=0.05)$. Just before being completely weaned (d 49), calves experiencing abrupt weaning were more efficient at digesting DM, $\mathrm{OM}$, and fat. Apparent $\mathrm{dC}$ of $\operatorname{ADF}(P=0.09)$ tended to be greater for gradual versus abrupt weaning. This indicates that GR calves, after reaching maximum MR consumption on d 15 and starting gradual weaning on d 28, had significantly increased digestion of more recalcitrant carbohydrates such as cellulose. Having greater starter consumption through GR weaning leads to a more developed rumen with a capability to digest fiber more efficiently. This is logical because GR calves also consumed more starter, and research shows that solid dry feed intake promotes microbial development and increases ruminal metabolic activity (Anderson et al., 1987), leading to a rumen that is more effective at digesting more complex nutrients such as fiber. There was also a rate $x$ weaning interaction trend observed for starch $\mathrm{dC}$; HI-AB tended to have a greater value compared with the other treatments. This is logical because HI-AB calves were offered a greater amount of MR for a longer period, which resulted in lower starter intake and higher retention time, which allowed the higher $\mathrm{dC}$ of soluble carbohydrates in the developing rumen.

\section{CONCLUSIONS}

Calves consuming a moderate amount of MR had increased starter consumption compared with those consuming a high amount, which is in line with the initial hypothesis. However, we also hypothesized a more functional rumen in calves fed moderate amounts of MR due to increased starter consumption, which would lead to greater nutrient digestion. This was the case for NDF, ADF, and sugar but not the case for $\mathrm{DM}, \mathrm{OM}$, and fat, which had greater apparent $\mathrm{dC}$ in HI calves. Calves consuming high amounts of $\mathrm{MR}$ also had increased FE, ADG, and growth parameters compared with those consuming moderate amounts, which was expected. Calves weaned abruptly also had lower starter intake as well as greater FE compared with calves weaned gradually, which can be attributed to the higher nutrient $\mathrm{dC}$ in MR. This would imply that increased MR promotes growth early in life and greater $\mathrm{FE}$ but that a moderate amount of MR promotes rumen development and, therefore, the digestion 
of fibrous feed fractions. Gradual weaning seems to be effective based on FE when used in high-MR feeding regimens.

\section{ACKNOWLEDGMENTS}

The authors thank members of the Clemson Ruminant Nutrition Team and personnel at the Provimi Nurture Research Center for their assistance throughout the duration of this project. The authors thank Provimi North America (Brookville, $\mathrm{OH}$ ). This work was supported by the USDA National Institute of Food and Agriculture (Washington, DC; NC-2042) and Provimi North America.

\section{REFERENCES}

Anderson, K. L., T. G. Nagaraja, J. L. Morrill, T. B. Avery, S. J. Galitzer, and J. E. Boyer. 1987. Ruminal microbial development in conventionally or early-weaned calves. J. Anim. Sci. 64:1215-1226.

AOAC International. 2000. Official Methods of Analysis. Vol. 1. 17th ed. AOAC International, Arlington, VA.

Baldwin, R. L. VI, K. R. McLeod, J. L. Klotz, and R. N. Heitmann. 2004. Rumen development, intestinal growth and hepatic metabolism in the pre- and postweaning ruminant. J. Dairy Sci. 87:E55E65.

Bartlett, K. S., F. K. McKeith, M. J. VandeHaar, G. E. Dahl, and J. K. Drackley. 2006. Growth and body composition of dairy calves fed milk replacers containing different amounts of protein at two feeding rates. J. Anim. Sci. 84:1454-1467.

Beharka, A. A., T. G. Nagaraja, J. L. Morrill, G. A. Kennedy, and R. D. Klemm. 1998. Effects of form of the diet on anatomical, microbial, and fermentative development of the rumen of neonatal calves. J. Dairy Sci. 81:1946-1955.

Calloway, C. D., J. W. Tyler, R. K. Tessman, D. Hostetler, and J. Holle. 2002. Comparison of refractometers and test endpoints in the measurement of serum protein concentration to assess passive transfer status in calves. J. Am. Vet. Med. Assoc. 221:1605-1608.

Chapman, C. E., T. M. Hill, D. R. Elder, and P. S. Erickson. 2017. Nitrogen utilization, preweaning nutrient digestibility, and growth effects of Holstein dairy calves fed 2 amounts of a moderately high protein or conventional milk replacer. J. Dairy Sci. 100:279-292.

Coverdale, J. A., H. D. Tyler, J. D. Quigley III, and J. A. Brumm. 2004. Effect of various levels of forage and form of diet on rumen development and growth in calves. J. Dairy Sci. 87:2554-2562.

Davis Rincker, L. E., M. J. VandeHaar, C. A. Wolf, J. S. Liesman, L. T. Chapin, and M. S. Weber Nielsen. 2011. Effect of intensified feeding of heifer calves on growth, pubertal age, calving age, milk yield, and economics. J. Dairy Sci. 94:3554-3567.

Dennis, T. S., F. X. Suarez-Mena, T. M. Hill, J. D. Quigley, R. L. Schlotterbeck, and L. Hulbert. 2018. Effect of milk replacer feeding rate, age at weaning, and method of reducing milk replacer to weaning on digestion, performance, rumination, and activity in dairy calves to 4 months of age. J. Dairy Sci. 101:268-278.

DuBois, M., K. A. Gilles, J. K. Hamilton, P. A. Rebers, and F. Smith. 1956. Colorimetric method for determination of sugars and related substances. Anal. Chem. 28:350-356.

FASS. 2010. Guide for the Care and Use of Agricultural Animals in Research and Teaching. FASS, Champaign, IL.

Flower, F. C., and D. M. Weary. 2001. Effects of early separation on the dairy cow and calf: 2 . Separation at 1 day and 2 weeks after birth. Appl. Anim. Behav. Sci. 70:275-284.

Gelsinger, S. L., and A. J. Heinrichs. 2017. Comparison of immune responses in calves fed heat-treated or unheated colostrum. J. Dairy Sci. 100:4090-4101.
Hall, M. B. 2009. Analysis of starch, including maltooligosaccharides, in animal feeds: A comparison of methods and a method recommended for AOAC collaborative study. J. AOAC Int. 92:42-49.

Hill, S. R., K. F. Knowlton, K. M. Daniels, R. E. James, R. E. Pearson, and A. V. Capuco. 2008a. Effects of milk replacer composition on growth, body composition, and nutrient excretion in preweaned Holstein heifers. J. Dairy Sci. 91:3145-3155.

Hill, T. M., H. G. Bateman II, J. M. Aldrich, and R. L. Schlotterbeck. 2007. Effects of the feeding rate of high protein calf milk replacers. Prof. Anim. Sci. 23:649-655.

Hill, T. M., H. G. Bateman II, J. M. Aldrich, and R. L. Schlotterbeck. 2010. Effect of milk replacer program on digestion of nutrients in dairy calves. J. Dairy Sci. 93:1105-1115.

Hill, T. M., H. G. Bateman, J. M. Aldrich, and R. L. Schlotterbeck. 2012. Methods of reducing milk replacer to prepare dairy calves for weaning when large amounts of milk replacer have been fed. Prof. Anim. Sci. 28:332-337.

Hill, T. M., H. G. Bateman II, J. M. Aldrich, R. L. Schlotterbeck, and K. G. Tanan. 2008b. Optimal concentrations of lysine, methionine, and threonine in milk replacers for calves less than five weeks of age. J. Dairy Sci. 91:2433-2442.

Hill, T. M., J. D. Quigley, H. G. Bateman II, F. X. Suarez-Mena, T. S. Dennis, and R. L. Schlotterbeck. 2016a. Effect of milk replacer program on calf performance and digestion of nutrients in dairy calves to 4 months of age. J. Dairy Sci. 99:8103-8110.

Hill, T. M., J. D. Quigley, F. X. Suarez-Mena, H. G. Bateman II, and R. L. Schlotterbeck. 2016b. Effect of milk replacer feeding rate and functional fatty acids on dairy calf performance and digestion of nutrients. J. Dairy Sci. 99:6352-6361.

Hill, T. M., M. J. VandeHaar, L. M. Sordillo, D. R. Catherman, H. G. Bateman II, and R. L. Schlotterbeck. 2011. Fatty acid intake alters growth and immunity in milk-fed calves. J. Dairy Sci. 94:39363948.

Jasper, J., and D. M. Weary. 2002. Effects of ad libitum milk intake on dairy calves. J. Dairy Sci. 85:3054-3058.

Khan, M. A., D. M. Weary, and M. A. G. von Keyserlingk. 2011. Invited review: Effects of milk ration on solid feed intake, weaning, and performance in dairy heifers. J. Dairy Sci. 94:1071-1081.

Kertz, A. F., and H. Chester-Jones. 2004. Invited review: Guidelines for measuring and reporting calf and heifer experimental data. J. Dairy Sci. 87:3577-3580.

Kertz, A. F., and J. R. Loften. 2013. Review: A historical perspective of specific milk-replacer feeding programs in the United States and effects on eventual performance of Holstein dairy calves. Prof. Anim. Sci. 29:321-332.

Kertz, A. F., L. R. Prewitt, and J. P. Everett. 1979. An early weaning calf program: Summarization and review. J. Dairy Sci. 62:18351843.

Khan, M. A., H. J. Lee, W. S. Lee, H. S. Kim, K. S. Ki, T. Y. Hur, G. H. Suh, S. J. Kang, and Y. J. Choi. 2007a. Structural growth, rumen development, and metabolic and immune responses of Holstein male calves fed milk through step-down and conventional methods. J. Dairy Sci. 90:3376-3387.

Khan, M. A., H. J. Lee, W. S. Lee, H. S. Kim, S. B. Kim, K. S. Ki, J. K. Ha, H. G. Lee, and Y. J. Choi. 2007b. Pre- and postweaning performance of Holstein female calves fed milk through step-down and conventional methods. J. Dairy Sci. 90:876-885.

Robertson, J. B., and P. J. Van Soest. 1981. The Detergent System of Analysis and its Application to Human Foods. Cornell University, Ithaca, NY

Stamey, J. A., N. A. Janovick, A. F. Kertz, and J. K. Drackley. 2012. Influence of starter protein content on growth of dairy calves in an enhanced early nutrition program. J. Dairy Sci. 95:3327-3336.

Steele, M. A., G. B. Penner, F. Chaucheyras-Durand, and L. L. Guan. 2016. Development and physiology of the rumen and the lower gut: Targets for improving gut health. J. Dairy Sci. 99:4955-4966.

Suárez, B. J., C. G. Van Reenen, G. Beldman, J. van Delen, J. Dijkstra, and W. J. J. Gerrits. 2006. Effects of supplementing concentrates differing in carbohydrate composition in veal calf diets: I. Animal performance and rumen fermentation characteristics. J. Dairy Sci. 89:4365-4375. 
Suarez-Mena, F. X., A. J. Heinrichs, C. M. Jones, T. M. Hill, and J. D. Quigley. 2015. Digestive development in neonatal dairy calves with either whole or ground oats in the calf starter. J. Dairy Sci. 98:3417-3431.

Suarez-Mena, F. X., T. M. Hill, A. J. Heinrichs, H. G. Bateman II, J. M. Aldrich, and R. L. Schlotterbeck. 2011. Effects of including corn distillers dried grains with solubles in dairy calf feeds. J. Dairy Sci. 94:3037-3044.

Sweeney, B. C., J. Rushen, D. M. Weary, and A. M. de Passillé. 2010 Duration of weaning, starter intake, and weight gain of dairy calves fed large amounts of milk. J. Dairy Sci. 93:148-152.

Tamate, H., A. D. McGilliard, N. L. Jacobson, and R. Getty. 1962. Effect of various dietaries on the anatomical development of the stomach in the calf. J. Dairy Sci. 45:408-420.

Terré, M., M. Devant, and A. Bach. 2007. Effect of level of milk replacer fed to Holstein calves on performance during the preweaning period and starter digestibility at weaning. Livest. Sci. 110:82-88.

Van Keulen, J. V., and B. A. Young. 1977. Evaluation of acid-insoluble ash as a natural marker in ruminant digestibility studies. J. Anim. Sci. 44:282-287.

Van Soest, P. J., J. B. Robertson, and B. A. Lewis. 1991. Methods for dietary fiber, neutral detergent fiber, non-starch polysaccharides in relation to animal nutrition. J. Dairy Sci. 74:3583-3597.
Wildman, E. E., G. M. Jones, P. E. Wagner, R. L. Boman, H. F. Troutt, and T. N. Lesch. 1982. A dairy cow body condition scoring system and its relationship to selected production characteristics. J. Dairy Sci. 65:495-501.

Wood, K. M., S. I. Palmer, M. A. Steele, J. A. Metcalf, and G. B. Penner. 2015. The influence of age and weaning on permeability of the gastrointestinal tract in Holstein bull calves. J. Dairy Sci. 98:7226-7237.

\section{ORCIDS}

R. N. Klopp (ํ) https://orcid.org/0000-0001-8485-6831

F. X. Suarez-Mena (ํ) https://orcid.org/0000-0002-1546-5893

T. S. Dennis (ํ) https://orcid.org/0000-0003-3424-5498

T. M. Hill ๑ https://orcid.org/0000-0003-1304-5016

R. L. Schlotterbeck ๑ https://orcid.org/0000-0002-5305-3945

G. J. Lascano @ https://orcid.org/0000-0002-9052-7935 